Article

\title{
Synthesis of Chalcone Using LDH/Graphene Nanocatalysts of Different Compositions
}

\author{
Mayra G. Álvarez ${ }^{1,2, *}$, Dana G. Crivoi ${ }^{1,+}{ }^{(\mathbb{D}}$, Francesc Medina ${ }^{1}$ (D) and Didier Tichit ${ }^{2, *}$ \\ 1 Chemical Engineering Dep., University Rovira i Virgili, 43007 Tarragona, Spain; \\ dana-georgiana.crivoi@chem.ox.ac.uk (D.G.C.); francesc.medina@urv.cat (F.M.) \\ 2 ICGM, Univ. Montpellier, CNRS, ENSCM, 240 Avenue du Professeur Emile Jeanbrau, \\ 34296 Montpellier CEDEX 5, France \\ * Correspondence: mayra.garcia@urv.cat (M.G.Á.); didier.tichit@enscm.fr (D.T.) \\ + Current address: Chemistry Research Laboratory, University of Oxford, 12 Mansfield Road, \\ Oxford OX1 3TA, UK.
}

Received: 19 January 2019; Accepted: 6 March 2019; Published: 9 March 2019

\begin{abstract}
Layered double hydroxides (LDH) or their derived mixed oxides present marked acid-base properties useful in catalysis, but they are generally agglomerated, inducing weak accessibility to the active sites. In the search for improving dispersion and accessibility of the active sites and for controlling the hydrophilic/hydrophobic balance in the catalysts, nanocomposite materials appear among the most attractive. In this study, a series of nanocomposites composed of LDH and reduced graphene oxide (rGO), were successfully obtained by direct coprecipitation and investigated as base catalysts for the Claisen-Schmidt condensation reaction between acetophenone and benzaldehyde. After activation, the LDH-rGO nanocomposites exhibited improved catalytic properties compared to bare LDH. Moreover, they reveal great versatility to tune the selectivity through their composition and the nature or the absence of solvent. This is due to the enhanced basicity of the nanocomposites as the LDH content increases which is assigned to the higher dispersion of the nanoplatelets in comparison to bulk LDH. Lewis-type basic sites of higher strength and accessibility are thus created. The nature of the solvent mainly acts through its acidity able to poison the basic sites of the nanocatalysts.
\end{abstract}

Keywords: Claisen-Schmidt condensation; reduced graphene oxide; layered double hydroxide; hydrotalcite; base catalysts; nanocomposites

\section{Introduction}

The design of hybrid materials with multifunctional properties through the combination of various building blocks is a growing topic in material science. Considerable attention is thus given to the development of nanohybrid materials composed of layered double hydroxides (LDH) and carbon based materials [1] such as carbon nanotubes (CNT), carbon nanofibers (CNF), multiwalled carbon nanotubes (MWCNT), graphene $(\mathrm{G})$ and chemically modified graphene such as graphene oxide (GO) [2]. The catalysts obtained by self-assembly of LDHs and (nano)carbon supports exhibit higher mechanical strength, surface area, thermal conductivity and chemical reactivity than the corresponding constituents. For instance, $\mathrm{LDH}$ /carbon fibers (CF) nanocomposites obtained by growing $\mathrm{MgAl}$ LDHs in situ on CF were efficient catalysts for the transesterification reaction of glycerol with diethyl carbonate into glycerol carbonate [3]. LDH crystals deposited inside a mesoporous carbon material (CMK-41) were highly active catalysts in Claisen-Schmidt condensation [4]. Winter et al. [5] and, more recently, Álvarez et al. [6] investigated the catalytic activity of MgAl-LDH/CNF nanocomposites. Their specific activities were more than four and hundred times higher in the acetone self-condensation and the glycerol transesterification with diethyl carbonate, respectively, than the unsupported 
LDHs. Similarly, MgAl-LDHs supported on MWCNT showed enhanced activity in the acetone self-condensation [7]. The common features of these hybrid materials are a small particle size and a good dispersion of the LDH active phase, together with other factors such as tunable polarity. It is believed that the immobilization of $\mathrm{LDH}$ on the surface of $\mathrm{GO}$ or reduced graphene oxide (rGO) support would produce highly efficient nanocatalysts. Indeed, the large surface area of the support allows for high dispersion of the LDH particles and thus of the active sites, and its high electrical conductivity will enhance the carrier mobility and improve the electron-hole separation efficiency of LDH. This latter feature is interesting for photocatalytic applications. The LDH-G, LDH-GO and LDH-rGO nanocomposites are used in various fields such as supercapacitors, water splitting, electrochemistry and photocatalysis among others [8]. However, applications involving C-C bond formation of great interest for fine chemistry applications are reported in much lesser extent. Ahmed et al. [9] reported the activity of $\mathrm{CuCo}-\mathrm{LDH} / \mathrm{rGO}$ materials in the $\mathrm{C}-\mathrm{C}$ coupling via Ullmann reaction, where the use of transition metal catalysts is required. In the same time, we presented a new application of $\mathrm{MgAl}-\mathrm{LDH} / \mathrm{rGO}$ structures as active solid base catalysts in C-C bond formation reaction [10]. In it, we have reported, that a nanocomposite with LDH:rGO mass ratio of 10 achieves the condensation of acetone at $0{ }^{\circ} \mathrm{C}$ with about $20 \%$ yield of diacetone alcohol, only slightly below the thermodynamic equilibrium (23.1\%). An influence of the synthesis method on the structure-activity relationship has been evidenced.

The Claisen-Schmidt condensation reaction between acetophenone and benzaldehyde leading to chalcone is a valuable $\mathrm{C}-\mathrm{C}$ bond-forming reaction, usually achieved with basic catalysts. This reaction is of great interest because a wide range of applications of chalcones, which are natural precursors of open chain flavonoids, are considered for the synthesis of many pharmaceutical compounds, fragrances, etc. Moreover, their biological properties include antibacterial, anti-inflammatory, antimalarial, antifungal, antiviral, antioxidant, mutagenic and cytotoxic activities, among the most significant [11]. Chalcones can exist in two isomeric forms, cis and trans, the trans-chalcone exhibiting special anti-cancerous properties [12,13]. Chalcones have been synthesized using different type of catalysts, solvents and temperatures. Various base catalysts were used such as $\mathrm{NaOH}-\mathrm{EtOH}$, or solids such as $\mathrm{K}_{2} \mathrm{CO}_{3}$, barium hydroxide, alumina, $\mathrm{MgO}$, alkali-exchanged zeolites, hydroxyapatites, activated carbons, mixed oxides obtained from LDH precursors and carbon supported LDHs [11-17] covering a wide range of basic strength. However, the selectivity to chalcone is generally low due to several side reactions leading particularly to Michael addition product. Interesting results were obtained using calcined-rehydrated $\mathrm{Mg} / \mathrm{Al} \mathrm{LDH}$ catalysts known to contain intercalated $\mathrm{OH}^{-}$anions acting as Brønsted basic sites. Lopez et al. [18] carried out the reaction at $0{ }^{\circ} \mathrm{C}$ in dimethylformamide (DMF) and reach $80 \%$ chalcone yield after $3 \mathrm{~h}$. On the other hand, the reaction has been performed without solvent by Climent et al. [15] reaching $98 \%$ yield of trans-chalcone after $4 \mathrm{~h}$ at $150{ }^{\circ} \mathrm{C}$. These calcined-rehydrated $\mathrm{Mg} / \mathrm{Al} \mathrm{LDH}$ catalysts were by far more active than the non-rehydrated $\mathrm{Mg}(\mathrm{Al}) \mathrm{O}$ mixed oxides obtained from calcined $\mathrm{Mg} / \mathrm{Al} \mathrm{LDHs}$ containing mainly $\mathrm{O}^{2-}-\mathrm{Mn}^{+}$acid-base pairs. Using such mixed oxide Guida et al. [19] reported $20 \%$ chalcone yield after $24 \mathrm{~h}$ when the reaction was carried out at $110^{\circ} \mathrm{C}$ in ethanol. However, a main drawback of the calcined-rehydrated LDHs is that the rehydration step is a delicate process. Therefore, the LDH/rGO nanocomposites with highly dispersed $\mathrm{Mg}(\mathrm{Al}) \mathrm{O}$ platelets of low size leading to a high density of low-coordinated $\mathrm{O}^{2-}$ sites which are able to achieve the self-condensation of acetone appear very attractive for the Claisen-Schmidt condensation reaction.

Here, we studied the condensation reaction between acetophenone and benzaldehyde using $\mathrm{LDH} / \mathrm{rGO}$ nanocatalysts whose LDH:rGO mass ratio has been varied between 0.5 and 20 in order to adjust the textural and the basic properties. Chalcone yields were particularly followed to determine the influence of the dispersion and of the low platelet sizes of the activated LDH phase in the LDH/rGO nanocatalysts in comparison to the bulk $\mathrm{Mg}(\mathrm{Al}) \mathrm{O}$ mixed oxide. As the influence of the solvent could be determinant, solvents of different nature have been investigated. Moreover, with the aim to develop a cleaner process, the reaction has been also studied in the absence of solvent. 


\section{Materials and Methods}

\subsection{Materials}

Natural flake graphite (carbon content: 99.8\%, 325 mesh) and $\mathrm{KMnO}_{4}(98 \%)$ were purchased from Alfa Aesar. $\mathrm{H}_{2} \mathrm{O}_{2}(30 \%), \mathrm{H}_{2} \mathrm{SO}_{4}(98 \%), \mathrm{NaNO}_{3}$ (analytical grade), $\mathrm{Mg}\left(\mathrm{NO}_{3}\right)_{2} \cdot 6 \mathrm{H}_{2} \mathrm{O}(99 \%)$, $\mathrm{Al}\left(\mathrm{NO}_{3}\right)_{3} \cdot 9 \mathrm{H}_{2} \mathrm{O}(98.5 \%), \mathrm{NaOH}(>97 \%)$ and $\mathrm{HCl}(37 \%)$ were purchased from Sigma-Aldrich and used without further purification. Deionized water was used throughout the experiments.

\subsection{Synthesis of $G O$}

GO is commonly used as an easily water-dispersible precursor to G or rGO. GO was synthesized using a modified Hummers method [20]. Typically, $10 \mathrm{~g}$ of natural graphite and $5 \mathrm{~g}$ of $\mathrm{NaNO}_{3}$ were added to $230 \mathrm{~mL}$ of $\mathrm{H}_{2} \mathrm{SO}_{4}$. The temperature of the mixture was kept at $5{ }^{\circ} \mathrm{C}$ and then $30 \mathrm{~g}$ of $\mathrm{KMnO}_{4}$ were slowly added into the suspension. After $30 \mathrm{~min}$, the temperature was increased to $35^{\circ} \mathrm{C}$ and the mixture was kept for another $30 \mathrm{~min}$ after which $460 \mathrm{~mL}$ of Milli-Q water was added. Then, the temperature was increased to $90{ }^{\circ} \mathrm{C}$ and the reaction was maintained for $1 \mathrm{~h}$. The resulted suspension was then diluted with another addition of $700 \mathrm{~mL}$ of $\mathrm{H}_{2} \mathrm{O}$ and, then, treated with $30 \mathrm{~mL}$ of a $30 \mathrm{wt} \% \mathrm{H}_{2} \mathrm{O}_{2}$ solution. The mixture was then cooled down to room temperature and repeatedly centrifuged and washed; first with a $5 \mathrm{wt} \% \mathrm{HCl}$ solution and then with $\mathrm{H}_{2} \mathrm{O}$ until the $\mathrm{pH}$ reached $\approx$ 5. The resulted solid was dried at $40{ }^{\circ} \mathrm{C}$. The GO dispersion in water $\left(2.5 \mathrm{mg} \mathrm{mL}^{-1}\right)$ was prepared by submitting the suspension to mechanical stirring for $1 \mathrm{~h}$ and subsequent ultrasonic treatment for $1 \mathrm{~h}$ to further exfoliate the GO. Stable brown colloidal suspension of GO layers was obtained after this treatment.

\subsection{Synthesis of $\mathrm{MgAl} \mathrm{LDH}$}

$3 \mathrm{MgAl} \mathrm{LDH}$ (corresponding to hydrotalcite group, i.e., $\mathrm{Mg} / \mathrm{Al}=3$ and $\mathrm{CO}_{3}{ }^{2-}$ as compensating anion) was synthesized by coprecipitation as described elsewhere [21]. Typically, $120 \mathrm{mmol}$ of $\mathrm{Mg}\left(\mathrm{NO}_{3}\right)_{2} \cdot 6 \mathrm{H}_{2} \mathrm{O}$ and $40 \mathrm{mmol}$ of $\mathrm{Al}\left(\mathrm{NO}_{3}\right)_{3} \cdot 9 \mathrm{H}_{2} \mathrm{O}$ were dissolved in $300 \mathrm{~mL}$ of distilled water and added dropwise into a glass vessel which initially contained $200 \mathrm{~mL}$ of deionized water. The $\mathrm{pH}$ was controlled by adding a $2 \mathrm{M} \mathrm{NaOH}+0.5 \mathrm{M} \mathrm{Na}_{2} \mathrm{CO}_{3}$ aqueous solution and kept at 10 . Both solutions were mixed under vigorous stirring and the white suspension was stirred overnight at $90{ }^{\circ} \mathrm{C}$. The precipitated solid was filtered and washed several times with water $(\approx 3 \mathrm{~L})$ until neutral $\mathrm{pH}$ and dried at $110^{\circ} \mathrm{C}$ for $24 \mathrm{~h}$.

\subsection{Synthesis of LDH-rGO Nanocomposites}

The LDH-rGO nanocomposites were synthesized by direct coprecipitation on the GO surface. The required amounts of metallic cationic nitrate salts $\left(\mathrm{Mg}\left(\mathrm{NO}_{3}\right)_{2} \cdot 6 \mathrm{H}_{2} \mathrm{O}\right.$ and $\mathrm{Al}\left(\mathrm{NO}_{3}\right)_{3} \cdot 9 \mathrm{H}_{2} \mathrm{O}, \mathrm{Mg} / \mathrm{Al}$ molar ratio $=3$ ) were added, in this case, to $100 \mathrm{~mL}$ of GO dispersed in water $\left(2.5 \mathrm{mg} \cdot \mathrm{mL}^{-1}\right)$ to obtain LDH-rGO hybrid materials with LDH:GO mass ratios of 0.5:1; 1:1; 2:1; 5:1; 10:1 and 20:1. Subsequently, a $2 \mathrm{M} \mathrm{NaOH}+0.5 \mathrm{M} \mathrm{Na}_{2} \mathrm{CO}_{3}$ aqueous solution was added to the mixture to fix the $\mathrm{pH}$ at 10 under continuous stirring. The resulting dark-brown suspension was aged at $90{ }^{\circ} \mathrm{C}$ for $12 \mathrm{~h}$. The basic media and the hydrothermal treatment allowed both the reduction of GO and the coprecipitation of LDH while the solution turned from brown to black. The suspension was centrifuged, washed several times with $\mathrm{H}_{2} \mathrm{O}$. The samples thus obtained were dried in static air at $80^{\circ} \mathrm{C}$. In the following they were noted as $\mathrm{LDH} / \mathrm{rGO}-\mathrm{x}$ with $\mathrm{x}$ representing the $\mathrm{LDH}: \mathrm{GO}$ mass ratio.

\subsection{Characterization Techniques}

Powder X-ray diffraction measurements (PXRD) were made in a Bruker-AXS D8-Discover diffractometer with a vertical theta-theta goniometer and a Vantec linear detector. Monochromatic $\mathrm{Cu} \mathrm{K} \alpha$ radiation was obtained from a copper $\mathrm{X}$-ray tube operated at $40 \mathrm{kV}$ and $40 \mathrm{~mA}$ and a $\mathrm{Ni}$ 
monochromator. Data were recorded over a $2 \theta$ range of $4-70^{\circ}$ with an angular step of $0.02^{\circ}$ at $10.6 \mathrm{~s} / \mathrm{step}$.

Specific surface areas were determined by $\mathrm{N}_{2}$ adsorption at $-196^{\circ} \mathrm{C}$ using a Micromeritics ASAP 2020 automatic analyzer. Samples were previously degassed in situ at $150^{\circ} \mathrm{C}$ under vacuum for $15 \mathrm{~h}$. Surface areas were calculated using the Brunauer-Emmet-Teller (BET) method over a $\mathrm{p} / \mathrm{p}_{0}$ range where a linear relationship was maintained.

Morphology of the samples was analyzed by electron microscopy. Transmission electron microscopy (TEM) was performed in the bright field using a JEOL JEM-2100 instrument at an accelerating voltage of $100 \mathrm{kV}$. The samples were prepared by dispersing the as-prepared catalysts in ethanol and then drop casting the suspension on a standard $3 \mathrm{~mm}$ holey copper grid and letting the ethanol evaporate at room temperature. Images were not filtered or treated by means of digital processing, and they correspond to raw data.

The actual LDH:rGO ratio was measured by thermogravimetric analysis (TGA) using a Perking Elmer Pyris STA 6000. Typically, $5 \mathrm{mg}$ samples were in situ dried at $80^{\circ} \mathrm{C}$ for $20 \mathrm{~min}$ and then heated from 80 to $900{ }^{\circ} \mathrm{C}$ at $10^{\circ} \mathrm{C} \cdot \mathrm{min}^{-1}$ in $20 \mathrm{~mL} \cdot \mathrm{min}^{-1}$ of air.

The basicity measurements were performed by volumetric adsorption of $\mathrm{CO}_{2}$ with a Micromeritics ASAP $2010 \mathrm{C}$ apparatus in the range $0-100 \mathrm{mmHg}$ at $30^{\circ} \mathrm{C}$. Samples were previously calcined in situ at $450{ }^{\circ} \mathrm{C}$ in vacuum for $5 \mathrm{~h}$. After calcination and evacuation of the sample, small increments of $\mathrm{CO}_{2}$ were introduced. Once the isotherm was achieved, evacuation at $10^{-7}$ Torr was performed and a second $\mathrm{CO}_{2}$ adsorption was done on the evacuated sample. The difference between the two isotherms allows calculating the amount of irreversibly chemisorbed $\mathrm{CO}_{2}$ molecules and then to determine more accurately the number of basic sites when not considering physisorbed $\mathrm{CO}_{2}$.

Thus, the total number of accessible basic sites was determined by taking the amount of $\mathrm{CO}_{2}$ chemisorbed at zero pressure $\left(\mathrm{cm}^{3} / \mathrm{g}\right.$ STP) obtained by extrapolation of the linear part of the second uptake isotherm.

\subsection{Catalytic Activity Tests}

The performance of the activated LDH/rGO nanocatalysts was evaluated in the Claisen-Schmidt condensation reaction between acetophenone and benzaldehyde. Activation of the nanocatalysts was performed by calcination at $450{ }^{\circ} \mathrm{C}\left(2{ }^{\circ} \mathrm{C} \mathrm{min}{ }^{-1}\right)$ under flowing $\mathrm{Ar}\left(70 \mathrm{~mL} \cdot \mathrm{min}^{-1}\right)$ for $5 \mathrm{~h}$. The Claisen-Schmidt condensation was performed in a $10 \mathrm{~mL}$ tube where a benzaldehyde/acetophenone ratio of 1.05 was added, along with the solvent (when used) and a $25 \%$ (in weight basis) of freshly activated catalyst. The mixture was stirred for $4 \mathrm{~h}$ at $40{ }^{\circ} \mathrm{C}$ (otherwise indicated). These operations were carried out under Ar atmosphere in order to exclude contact with atmospheric carbon dioxide. The catalyst was recovered by centrifugation and washed several times with the solvent, and the reaction medium was submitted to reduced pressure to remove the solvent when this was used. The products were both identified and quantified by ${ }^{1} \mathrm{H}-\mathrm{NMR}$.

\section{Results and Discussion}

\subsection{Materials Characterization}

As displayed in Table 1, the LDH content in the different LDH/rGO nanocomposites determined by TG analysis is close to the nominal values demonstrating the complete coprecipitation of the magnesium and aluminium nitrate salts in presence of GO.

PXRD patterns of the prepared LDH/rGO hybrids are presented in Figure 1A. They display the typical reflections corresponding to $2 \mathrm{D} \mathrm{LDH}$ materials with particularly the most intense harmonic (003) and (006) reflections in the $2 \theta$ range below $30^{\circ}$. The interlayer distance $\left(\mathrm{d}_{003}\right)$ of $0.772 \mathrm{~nm}$ is consistent with the presence of carbonate anions into the interlayer space provided by the alkaline synthesis solution $\left(\mathrm{NaOH}+\mathrm{Na}_{2} \mathrm{CO}_{3}\right)[22]$. 
Table 1. Layered double hydroxides (LDH) loading, textural and structural data of the synthesized $\mathrm{LDH} / \mathrm{rGO}$ nanocomposites.

\begin{tabular}{|c|c|c|c|c|c|c|}
\hline \multirow{2}{*}{ Sample } & \multirow{2}{*}{$\begin{array}{c}\text { LDH:rGO } \\
\text { Nominal }\end{array}$} & \multicolumn{2}{|c|}{ LDH Content wt. $\%$} & \multirow{2}{*}{$\begin{array}{l}\text { Integral Breadth } \\
\text { (deg.) }\end{array}$} & \multirow{2}{*}{$\begin{array}{l}\text { Cristallite } \\
\text { Size }(\mathrm{nm})^{b}\end{array}$} & \multirow{2}{*}{$\begin{array}{c}\mathrm{S}_{\mathrm{BET}} \\
\left(\mathrm{m}^{2} \cdot \mathrm{g}^{-1}\right)^{\mathrm{c}}\end{array}$} \\
\hline & & Nominal & Actual ${ }^{a}$ & & & \\
\hline $\mathrm{LDH} / \mathrm{rGO}-0.5$ & 0.5 & 33 & 37 & $1.210_{(003)}$ & n.d. & 25 \\
\hline $\mathrm{LDH} / \mathrm{rGO}-1$ & 1 & 50 & 49 & $\begin{array}{l}1.148_{(003)} \\
0.578_{(110)}\end{array}$ & $\begin{array}{l}7.8_{(003)} \\
5.8_{(110)}\end{array}$ & $\begin{array}{c}148 \\
(206)\end{array}$ \\
\hline $\mathrm{LDH} / \mathrm{rGO}-2$ & 2 & 67 & 65 & $\begin{array}{l}0.846_{(003)} \\
0.388_{(110)}\end{array}$ & $\begin{array}{l}10.1_{(003)} \\
9.4_{(110)}\end{array}$ & $\begin{array}{c}158 \\
(221)\end{array}$ \\
\hline $\mathrm{LDH} / \mathrm{rGO}-5$ & 5 & 83 & 81 & $\begin{array}{l}0.531_{(003)} \\
0.432_{(110)}\end{array}$ & $\begin{array}{c}12.9_{(003)} \\
7.7_{(110)}\end{array}$ & $\begin{array}{c}135 \\
(276)\end{array}$ \\
\hline $\mathrm{LDH} / \mathrm{rGO}-10$ & 10 & 91 & 91 & $\begin{array}{l}0.693_{(003)} \\
0.341_{(110)}\end{array}$ & $\begin{array}{l}11.6_{(003)} \\
7.5_{(003)}\end{array}$ & $\begin{array}{c}143 \\
(239)\end{array}$ \\
\hline $\mathrm{LDH} / \mathrm{rGO}-20$ & 20 & 95 & 95 & $\begin{array}{l}0.572_{(003)} \\
0.445_{(110)}\end{array}$ & $\begin{array}{c}8.8_{(003)} \\
15.4_{(110)}\end{array}$ & $\begin{array}{c}133 \\
(293)\end{array}$ \\
\hline $\mathrm{LDH}$ & - & 100 & 100 & $\begin{array}{l}0.349_{(003)} \\
0.306_{(110)}\end{array}$ & $\begin{array}{l}25.1_{(003)} \\
15.9_{(110)}\end{array}$ & $\begin{array}{c}140 \\
(280)\end{array}$ \\
\hline GO & - & - & - & - & - & 34 \\
\hline rGO & - & - & - & - & - & 3 \\
\hline
\end{tabular}

a Computed from TG analysis $\left(20 \mathrm{~mL} \cdot \mathrm{min}^{-1}\right.$ air, temperature range $80-900{ }^{\circ} \mathrm{C}$, temperature rate $10{ }^{\circ} \mathrm{C} \mathrm{min}^{-1}$.

${ }^{\mathrm{b}}$ Crystallite size calculated through Scherrer equation using either (003) or (110) planes using DIFFRACT.EVA software. The instrumental resolution function has been estimated with $\mathrm{LaB}_{6}$ (NIST 660a). Calculated crystallite size in sample with lowest $\mathrm{LDH}$ content (LDH/rGO-0.5) was excluded due to large estimation error. ${ }^{\mathrm{c}}$ The surface area of calcined materials is presented in brackets.
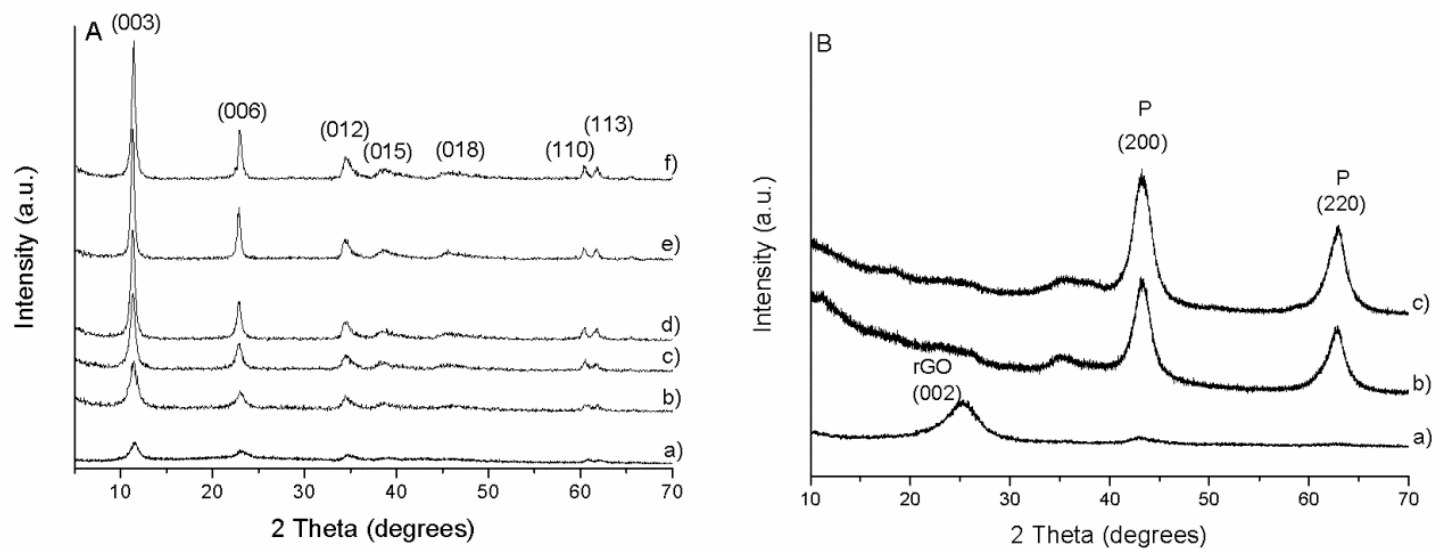

Figure 1. (A) PXRD of the as-prepared LDH/rGO nanocomposites: a) LDH/rGO-0.5; b) LDH/rGO-1; c) $\mathrm{LDH} / \mathrm{rGO}-2$; d) $\mathrm{LDH} / \mathrm{rGO}-5$; e) $\mathrm{LDH} / \mathrm{rGO}-10$ and f) $\mathrm{LDH} / \mathrm{rGO}-20$. (B) Calcined LDH/rGO nanocomposites: a) LDH/rGO-0.5; b) LDH/rGO-5 and c) LDH/rGO-10 (P stands for periclase phase).

As could be expected, the intensity and the shape of the LDH peaks depend on the LDH:rGO mass ratio. The intensity of the peaks decreases and the breadth increases with the decrease of the LDH content (Table 1), indicating an apparent decrease of crystallinity. This is in accordance with the behaviour previously reported by Garcia-Gallastegui et al. [23] and assigned not only to the increased GO contribution but mainly to the electrostatic interactions between GO and LDH during synthesis. This interaction influences the nucleation and then the crystallite size of the LDH particles. The absence of the basal reflection at $2 \theta=11.3^{\circ}$, typical of GO, indicates its reduction into rGO upon hydrothermal treatment. This was further confirmed through analysis of bare GO submitted to the same treatment (figure not shown), where a shift is observed from the intense peak at $2 \theta \sim 12^{\circ}$ for GO to a broad peak at $25-30^{\circ}$ assigned to rGO. Moreover, the absence of a marked background in the $2 \theta$ range $25-35^{\circ}$ in the nanocomposites indicates that the LDH nanoplatelets prevent the restacking of the rGO 
sheets. This suggests that the two components are intimately in contact and highly dispersed [24]. The well-defined (110) and (113) peaks of the LDH structure observed in the high angle region reveal that the structure of the layers is preserved in the nanocomposites. A deeper analysis of these peaks also reveals an increase in the breath with the increase in the rGO content, as previously seen with (003) basal peak, indicating a decrease in crystallinity not only along the xz plane, but also in the xy plane. Crystallite size was calculated by applying the Scherrer equation with (003) basal plane or (110) plane, confirming this assumption (Table 1). That is, the LDH crystallites in the nanocomposite are smaller and less stacked than in bare LDH. In all samples the lattice $a$ parameter of $0.306 \mathrm{~nm}$ calculated from the position of the (110) peak $\left(\mathrm{a}=2 \mathrm{~d}_{110}\right)$ is in agreement with a $\mathrm{Mg} / \mathrm{Al}$ molar ratio of 3 [25].

After calcination at $450{ }^{\circ} \mathrm{C}$ the $\mathrm{LDH} / \mathrm{rGO}$ composite materials lost the hydrotalcite-like layered structure. Figure 1B shows the PXRD patterns of the calcined composites which exhibit different shapes in function of the LDH content as illustrated by the representative LDH/rGO-0.5, LDH/rGO-5 and $\mathrm{LDH} / \mathrm{rGO}-10$ materials. Calcined LDH/rGO-5 and LDH/rGO-10 samples show reflections at $2 \theta \sim 43^{\circ}$ and $63^{\circ}$, corresponding to a periclase-like structure (JCPDS 87-0653) typical of a $\mathrm{Mg}(\mathrm{Al}) \mathrm{O}$ mixed oxide obtained by thermal decomposition of $\mathrm{Mg} / \mathrm{Al} \mathrm{LDH}$. The calcined LDH/rGO-0.5 material presents a broad reflection at $2 \theta \sim 25^{\circ}$ corresponding to rGO sheets. The absence of other peaks corresponding to periclase-like structure is due to both the low LDH content in the parent sample and to its high dispersion on the rGO surface.

Textural and structural data of the nanocomposites are reported in Table 1. All nanocomposite samples, as well as the bulk LDH show a type IV adsorption isotherm typical of mesoporous materials with a H4 hysteresis loop (except LDH/rGO-1) corresponding to slit-shaped mesopores which is normally observed in materials with aggregates of plate-like particles. Instead, sample LDH/rGO-1 displays a hysteresis loop of type $\mathrm{H}_{2}$, which is typical of either disordered materials or bottleneck constrictions (Figure 2). Remarkably, the specific surface areas varied slightly between 133 and $148 \mathrm{~m}^{2} \cdot \mathrm{g}^{-1}$ for the nanocomposites with LDH:rGO ratios ranging from 20:1 to 1:1 and are rather similar to that of the bare LDH $\left(140 \mathrm{~m}^{2} \cdot \mathrm{g}^{-1}\right)$. Due to the low surface area presented by rGO, as generally reported [23], a decrease of specific surface area could be expected in the LDH/rGO composite materials with the decrease of LDH content. The rather similar specific surface areas observed suggest, on the contrary, the formation of homogeneous structure in materials with LDH:rGO $\geq 1$. Therefore, as the LDH content increases, dispersion of the LDH platelets on the rGO surface may be improved and/or the GO restacking is reduced by the alternative LDH/GO stacking interactions as previously suggested [10,23]. The specific surface area decreases to $25 \mathrm{~m}^{2} \cdot \mathrm{g}^{-1}$ at low $\mathrm{LDH}$ content for the $\mathrm{LDH} / \mathrm{rGO}-0.5$ composite, well below the specific surface area of the bare LDH, accounting for high aggregation of the LDH particles which, in addition, do not hinder the restacking of the GO layers.
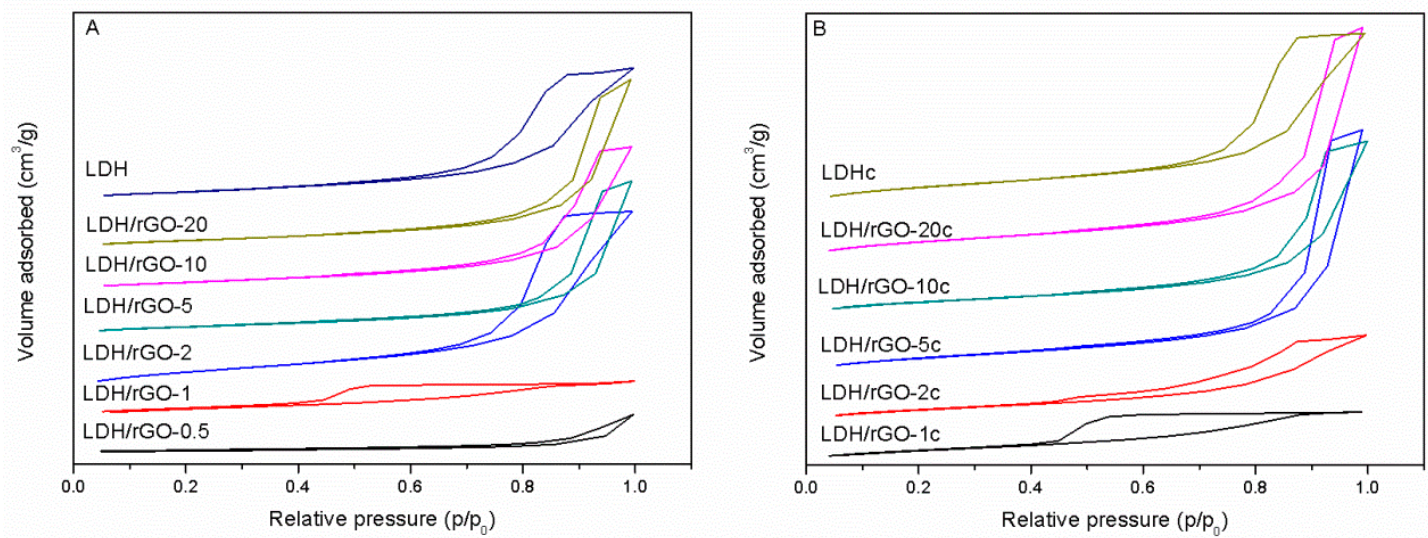

Figure 2. $\mathrm{N}_{2}$ adsorption-desorption isotherms of: (A) as-synthesized LDH and LDH/rGO materials and (B) $\mathrm{LDH}$ and $\mathrm{LDH} / \mathrm{rGO}$ materials after treatment at $450{ }^{\circ} \mathrm{C}$ under Ar for $5 \mathrm{~h}$. (Isotherms are displaced along ordinate axis to a better lecture). 
The behaviour observed for the nanocomposites with LDH:rGO $\geq 1$ has been also confirmed by SEM and TEM analysis (Figure 3). The samples are indeed constituted by GO or rGO sheets and relatively well dispersed LDH aggregates in contact displaying a house-of-cards-type structure which suggests the formation of mesopores. This is observed especially in those samples with higher LDH content, as previously reported in recent studies [10], while at low LDH content, sample LDH/rGO-1 yet presented a more stacked structure. At very low LDH content, LDH/rGO-0.5 has the lowest specific surface area in the series $\left(25 \mathrm{~m}^{2} \cdot \mathrm{g}^{-1}\right)$ suggesting the formation of a poorly porous material with highly packed LDH and rGO sheets (Figure 4). SEM and TEM analyses indeed confirms such highly packed structure where rGO and LDH phases are in intimate contact, although the existence of completely separated LDH and rGO domains is also clearly seen. The high homogeneity and dispersion of the LDH platelets in contact with rGO in samples with higher LDH content merits to be highlighted. Figure 5 shows HRTEM analysis of sample LDH/rGO-10 where LHD crystals appeared intimately assembled into the rGO. Besides, the lattice-fringe image shows the different phases occurrence. Lattice fringes at $3.5 \AA$ correspond to the (002) crystallographic planes of graphene, whereas straight planes at 2.28 and $1.95 \AA$ A corresponds to LDH.
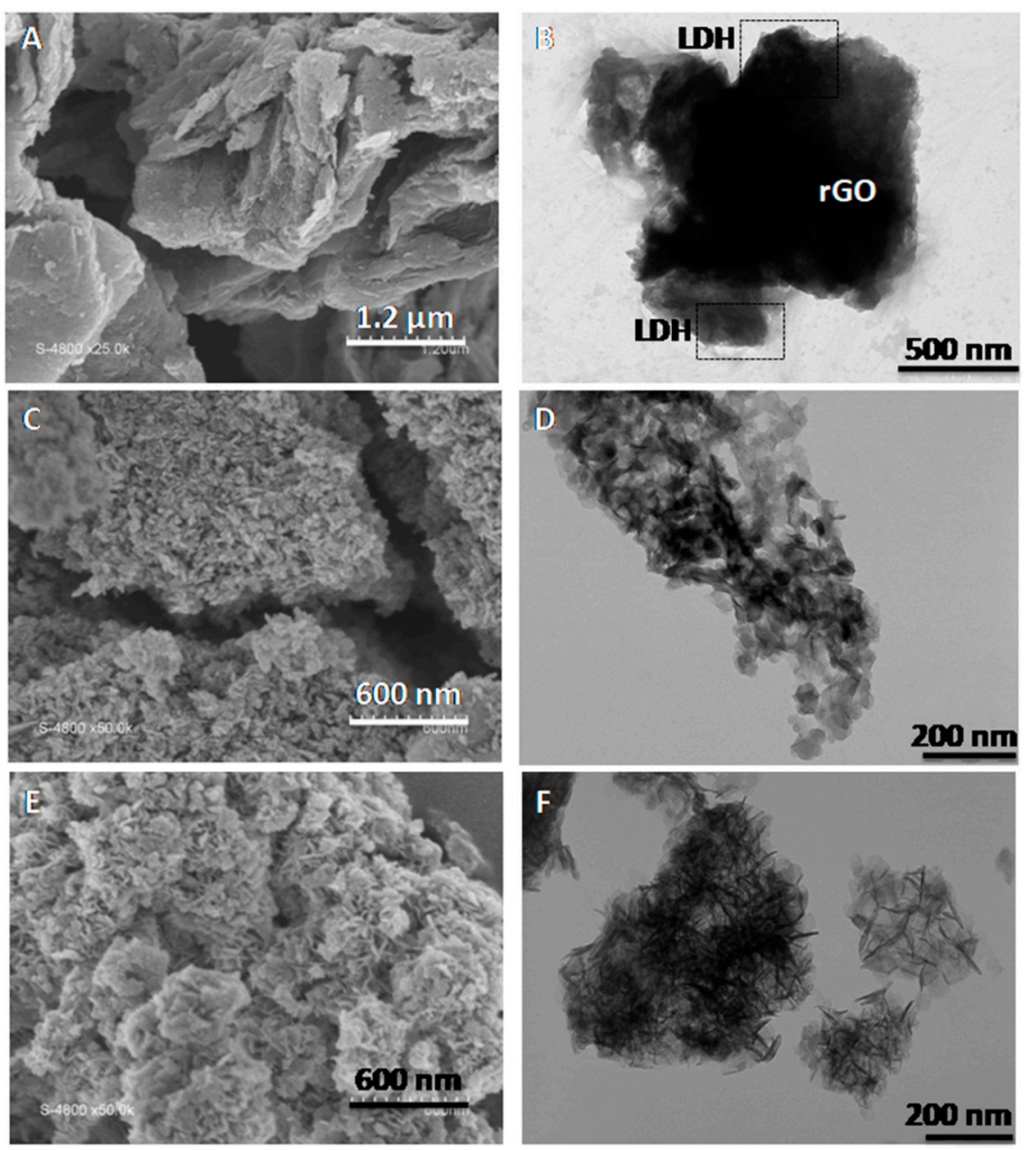

Figure 3. SEM and TEM micrographies of LDH/rGO-1 (A,B), LDH/rGO-10 (C,D) and LDH/rGO-20 (E,F). 

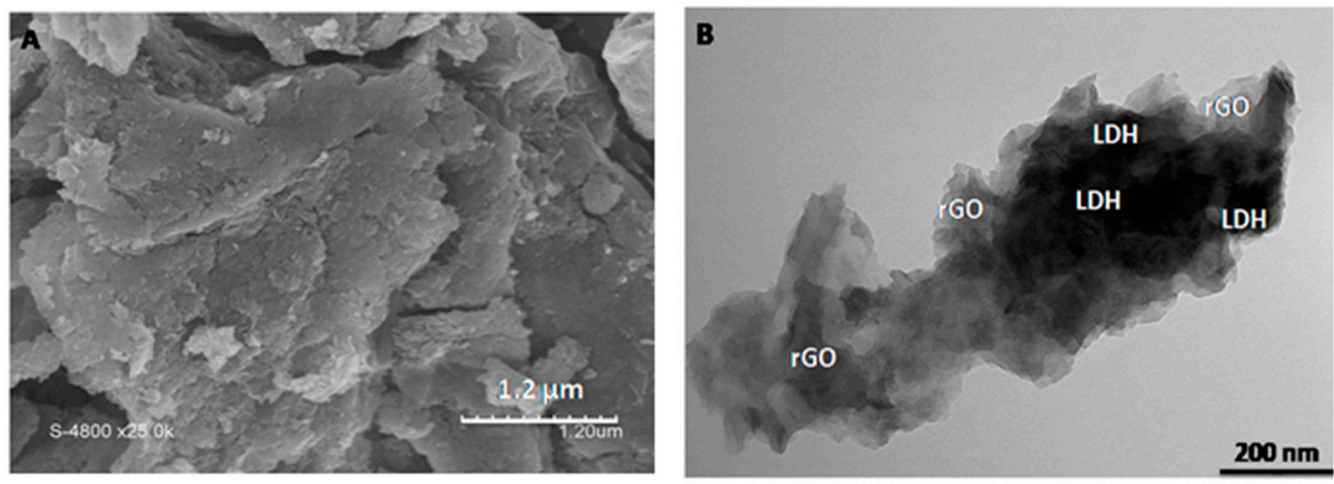

Figure 4. SEM micrography (A) and TEM micrography (B) of sample of sample LDH/rGO-0.5.
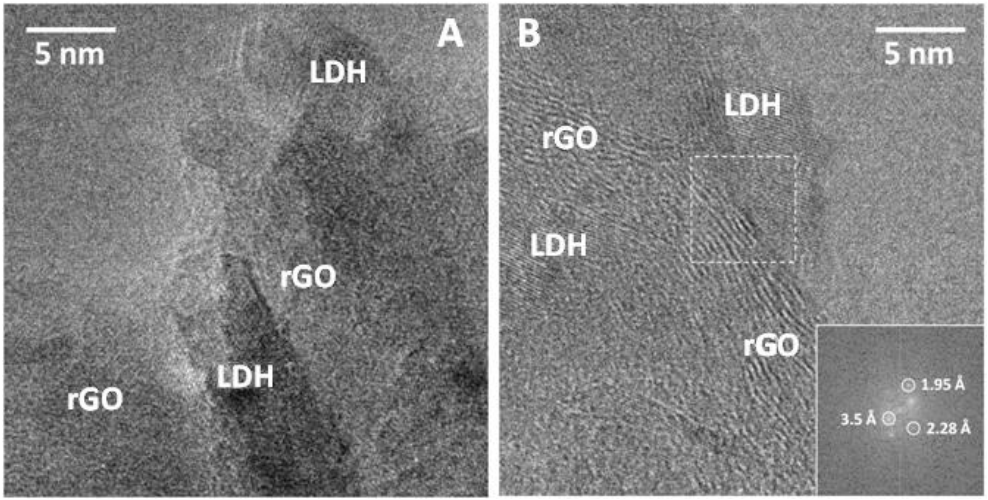

Figure 5. HRTEM of sample LDH/rGO-10 (A) showing the good dispersion and contact between components and (B) detailed structural HRTEM analisyis.

After calcination at $450{ }^{\circ} \mathrm{C}$, the values of the specific surface areas increase up to 1.4 and 2.2 times at low (LDH/rGO-1) and high (LDH/rGO-20) LDH content, respectively, in comparison to the non-calcined nanocomposites. This is in agreement with the structural transformation of the $\mathrm{Mg}-\mathrm{Al}$ $\mathrm{LDH}$ component into $\mathrm{Mg}(\mathrm{Al}) \mathrm{O}$ mixed oxide of higher surface area as confirmed with the bare $\mathrm{LDH}$ whose specific surface area increases from 140 to $280 \mathrm{~m}^{2} \cdot \mathrm{g}^{-1}$.

This suggests that the steadiness of the surface area in non-calcined hybrids may be related (in different extent) to both intrinsic porosity generated by incorporation of LDH in the hybrids as well as interporosity due to the lower stacking degree of both components (i.e., rGO and LDH) forming the nanocomposite. Whereas, the increase in surface area in calcined materials is due to the pore generation produced by gas release during the LDH decomposition upon thermal treatment confirmed by XRD (Figure 1).

Volumetric adsorption of $\mathrm{CO}_{2}$ at low pressure was applied to determine the number of basic sites on the $\mathrm{LDH} / \mathrm{rGO}$ nanocomposites activated by in situ calcination at $450{ }^{\circ} \mathrm{C}$. The amount of $\mathrm{CO}_{2}$ adsorbed and then the number of basic sites significantly increases from 52 to $265 \mu \mathrm{mol} \cdot \mathrm{g}^{-1}$ with the LDH content in the nanocomposites (Table 2). This is in accordance with earlier studies on basicity characterization of $\mathrm{LDH} / \mathrm{rGO}$ nanocomposites $[10,23,26]$.

In the analysis conditions of our experiments, the $\mathrm{CO}_{2}$ adsorption capacity of the bare $\mathrm{rGO}$ was found negligible. It is notable that $\mathrm{CO}_{2}$ adsorption capacity of sample $\mathrm{LDH} / \mathrm{rGO}-0.5$ was around two times lower than that reached by the activated bare LDH and LDH/rGO-1 samples. This is consistent with the morphology and texture of $\mathrm{LDH} / \mathrm{rGO}-0.5$ giving rise to low accessibility of the probe to the basic sites. On the other hand, the $\mathrm{CO}_{2}$ adsorption capacity of the samples having the highest $\mathrm{LDH}$ content, i.e., $\mathrm{LDH} / \mathrm{rGO}-10$ and $\mathrm{LDH} / \mathrm{rGO}-20$ is two-fold higher than that reached by the calcined LDH of similar specific surface area. One can suggest that, due to the high dispersion of the LDH layers in the parent nanocomposites, both the number of coordinatively unsaturated $\mathrm{O}^{2-}$ sites at the edge of the 
mixed oxide platelets and their accessibility are enhanced after activation. When the $\mathrm{CO}_{2}$ adsorption of nanocomposite materials is normalized per mass of $\mathrm{LDH}$, it results in values significantly higher for all of them than for the bulk LDH, similarly to what has been reported for LDHs supported on CF [3], CNF [5,6] or MWCNT [27].

Table 2. Basicity results of the synthesized LDH and LDH/rGO nanocomposites.

\begin{tabular}{ccc}
\hline Sample & $\begin{array}{c}\mathbf{C O}_{2} \text { Adsorbed } \\
\left(\boldsymbol{\mu} \mathbf{m o l C O}_{\mathbf{2}} \mathbf{g}_{\mathbf{m a t}}\right)\end{array}$ & $\begin{array}{c}\text { Normalized Adsorption } \\
\left(\boldsymbol{\mu} \mathbf{m o l C O} \mathbf{C}_{\mathbf{2}} \mathbf{g}_{\mathbf{L H}}\right)\end{array}$ \\
\hline $\mathrm{LDH} / \mathrm{rGO}-0.5$ & $52 \pm 3$ & 141 \\
$\mathrm{LDH} / \mathrm{rGO}-1$ & $109 \pm 5$ & 222 \\
$\mathrm{LDH} / \mathrm{rGO}-5$ & $128 \pm 1$ & 196 \\
$\mathrm{LDH} / \mathrm{rGO}-10$ & $221 \pm 2$ & 243 \\
$\mathrm{LDH} / \mathrm{rGO}-20$ & $265 \pm 2$ & 279 \\
$\mathrm{LDH}$ & $129 \pm 9$ & 129 \\
\hline \multicolumn{3}{c}{}
\end{tabular}

\subsection{Claisen-Schmidt Reaction}

The Claisen-Schmidt condensation reaction between acetophenone and benzaldehyde in basic conditions can lead to different products: the chalcone isomers, i.e., trans-chalcone (1) and cis-chalcone (2), the Michael addition product (1,3,5-triphenylpentan-1-5-dione) (3) and the aldol addition product (4), as can be seen from Scheme 1.

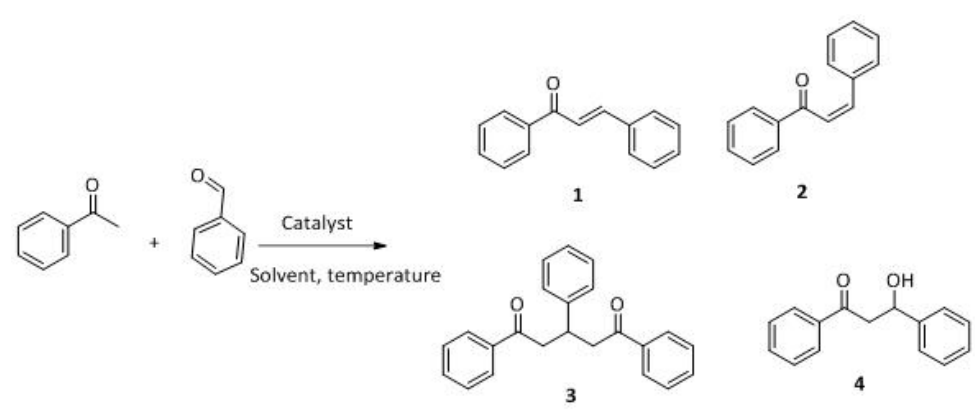

Scheme 1. Possible products resulting from Claisen-Schmidt condensation reaction.

The generally accepted base-catalysed mechanism of Claisen-Schmidt condensation reaction starts with the abstraction of the acidic $\alpha$-hydrogen of the ketone molecule by a base; the formed species undergoes a keto-enol tautomerism. The rate determining step of the entire reaction is the nucleophilic addition of the enolate, the anion of acetophenone, to the carbonyl carbon of the benzaldehyde, yielding the intermediate $\beta$-hydroxyl ketone, followed by dehydration to give chalcone (Scheme 2).

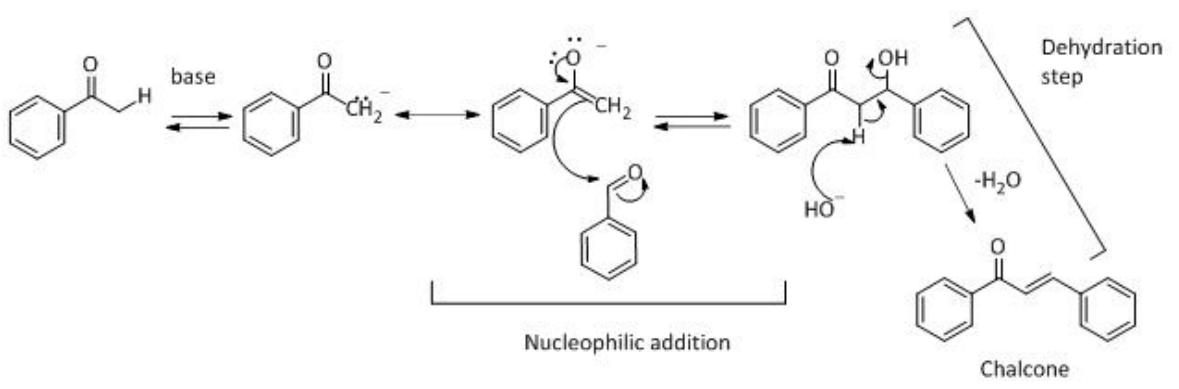

Scheme 2. Accepted mechanism of the Claisen-Schmidt condensation.

The solvent where a chemical reaction takes place is rarely a non-inert medium. Its complex interactions with solute molecules and possible intermediates can result in a modification of the 
reaction pathway. In our study we have chosen three different solvents, i.e. polar methanol $(\mathrm{MeOH})$, polar aprotic acetonitrile (ACN) and non-polar toluene whose physical constants are depicted in Table 3.

Table 3. Physical constants of the solvents studied in the Claisen-Schmidt condensation reaction.

\begin{tabular}{ccccc}
\hline Solvent & Type & Dielectric Constant & Dipole Moment & $\mathbf{p K}_{\mathbf{a}}$ \\
\hline $\mathrm{MeOH}$ & Polar protic & 33 & 1.7 & 15.5 \\
ACN & Polar aprotic & 37.5 & 3.92 & 25 \\
Toluene & Non-polar & 2.38 & 0.63 & 41 \\
\hline
\end{tabular}

The different products yields can allow more finely defining the influence of the textural properties and the basicity of the catalysts, particularly when one considers that formation of Michael addition product accounts for the presence of strong basic sites and/or for diffusional limitations favouring consecutive reactions. The production of Michael addition product also enhances with the temperature $[15,28]$.

The reaction carried out at $40{ }^{\circ} \mathrm{C}$ in the different solvents and in absence of solvent with the activated $\mathrm{LDH} / \mathrm{rGO}$ nanocatalysts allows reaching $100 \%$ conversion after $4 \mathrm{~h}$ in all cases while the conversion with the calcined LDH reaches values rather close to $100 \%$ after $8 \mathrm{~h}$. Such differences of activity between the $\mathrm{LDH} / \mathrm{rGO}$ nanocatalysts and the calcined LDH are in agreement with those previously reported for the acetone self-condensation [10]. For the chalcone synthesis Climent et al. reported conversions of $4 \%$ and $82 \%$ after $1 \mathrm{~h}$ at $50{ }^{\circ} \mathrm{C}$ without solvent with the calcined and the calcined-rehydrated LDH sample, respectively, while Lopez et al. reported conversions of $4.6 \%$ and $70 \%$, respectively, with the same type of catalysts after $3 \mathrm{~h}$ at $150{ }^{\circ} \mathrm{C}$ in DMF $[15,18]$. Although the reaction was performed in different conditions (temperature, catalyst/reactants mass ratio, reaction time), it is noteworthy that the LDH/rGO nanocomposites and the calcined-rehydrated LDHs are both more active than the calcined $\mathrm{LDH}$, i.e. the $\mathrm{Mg}(\mathrm{Al}) \mathrm{O}$ mixed oxide. In the case of rehydrated $\mathrm{LDH}$, this enhancement in activity has been attributed to the presence of intercalated $\mathrm{OH}^{-}$anions acting as Brönsted basic sites known to be the most active in aldol-type reactions. These reactions are indeed usually performed with $\mathrm{NaOH}$ or $\mathrm{KOH}$ in homogeneous catalysis. In our case, the increase in activity with the LDH/rGO nanocomposites respect to the calcined LDH likely accounts for an increase of the number and availability of the Lewis-type basic sites. rGO and LDH/rGO-0.5, the nanocomposite containing the lower amount of $\mathrm{LDH}$, were not active in the condensation reaction of acetophenone and benzaldehyde, in accordance with the behaviour previously reported for acetone self-condensation reaction [10]. Thus, in the following we will only consider the results from the nanocomposites with LDH:rGO $\geq 1$.

The selectivities obtained after $8 \mathrm{~h}$ with the bare $\mathrm{LDH}$ calcined at $450{ }^{\circ} \mathrm{C}$ reveal the influence of the presence of solvent and of its nature (Table 4). Without solvent trans-chalcone (1) and Michael addition product (3) were obtained accounting for the presence in the catalyst of strong basic sites able to achieve the consecutive reaction between acetophenone and chalcone. The differences of selectivities observed with $\mathrm{ACN}$ and methanol cannot be related to their dielectric constant and are more likely related to their respective acidities. $\mathrm{ACN}$ of weak acidity poisons the stronger basic sites thus slightly decreasing the formation of the Michael addition product in comparison to the reaction without solvent. Moreover, as ACN is a polar aprotic solvent, hydrogen bonds with the anionic adducts, i.e. the enolate anion, are hindered during the reaction. The interaction between the non-solvated anion and the surface of the catalysts is thus favoured and consequently improves the formation of chalcone.

Methanol, a polar solvent of higher acidity than ACN, also poisons the basic sites of medium strength. The formation of aldol (4) as only side-product suggests that the dehydration step of the Claisen-Schmidt condensation is inhibited. This reaction proceeds by an E1cB mechanism (Scheme 3), in two steps. In the first step the basic site abstracts a proton from the $\alpha-\mathrm{C}$ resulting in a carbanion which, in the second step, forms a $\pi$-bond and push the leaving group producing chalcone. 
Table 4. Product yields with bulk LDH after $8 \mathrm{~h}$ of reaction at $40{ }^{\circ} \mathrm{C}$ in the different solvents media.

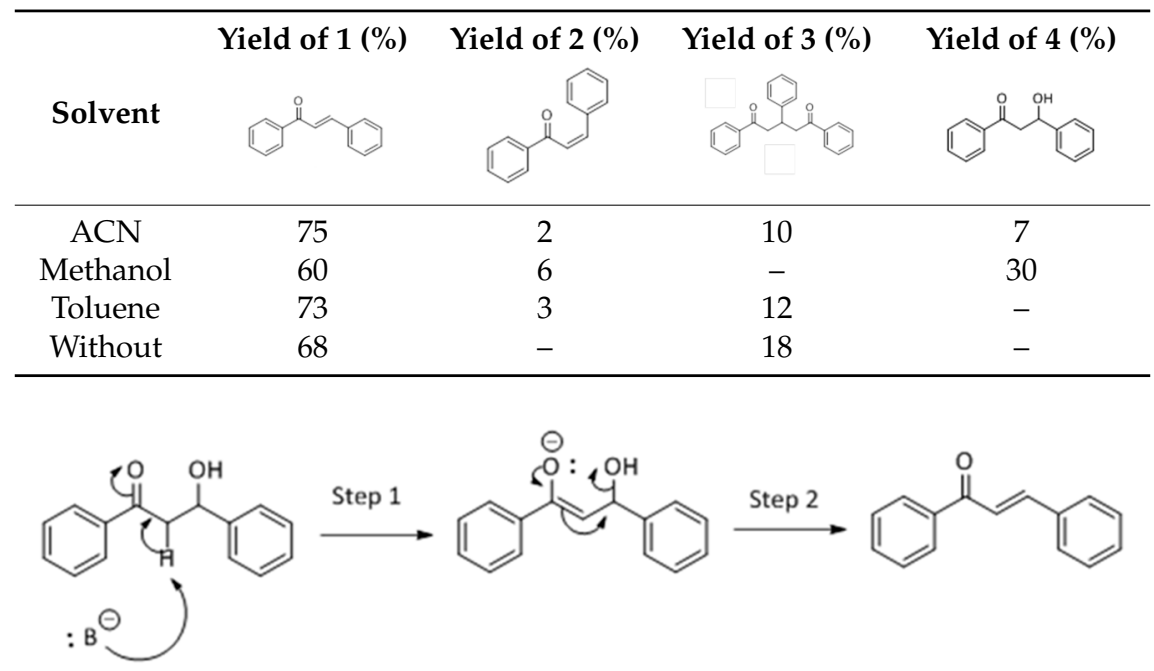

Scheme 3. The E1cB mechanism involved in the chalcone formation.

This E1cB mechanism is strongly favored in presence of a strong base, but the use of a slightly acidic solvent might poison the basic centers. Likewise, the anion formed in the first step of reaction (see Scheme 3) may abstract a proton from $\mathrm{MeOH}$ thus inhibiting the reactivity towards the elimination step. Therefore, the selectivity towards chalcone decreases and that towards aldol product increases as the poisoning of the basic sites by methanol increases. Consequently, chalcone is produced in lower yield than with ACN and at the expense of the aldol product (4), while formation of the Michael addition product (3) is totally inhibited.

Toluene behaves similarly to ACN leading to chalcone (1 and 2) and Michael addition product (3). This accounts also for its very weak acidity and, probably, for differences of adsorption of the reactants with this non polar solvent.

A similar general behaviour is observed with the $\mathrm{LDH} / \mathrm{rGO}$ catalysts than with the calcined LDH with differences depending on the composition of the nanocomposites (Tables 5-7). Chalcone is the main product observed without solvent as well as with $\mathrm{ACN}$ and toluene as solvents.

Table 5. Product yields after $4 \mathrm{~h}$ of reaction in aprotic acetonitrile (ACN) at $40{ }^{\circ} \mathrm{C}$ for all activated catalysts.

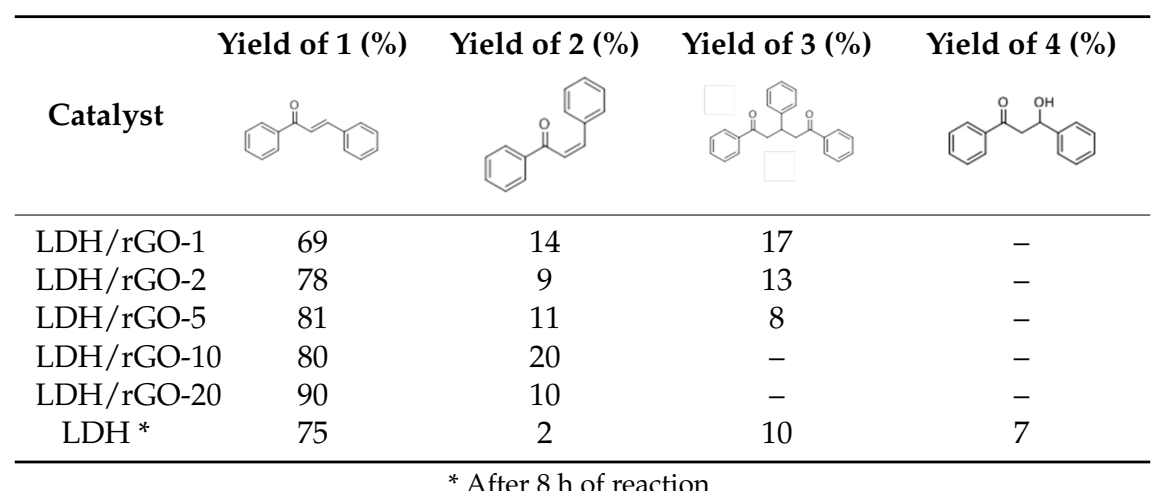

The higher selectivity towards chalcone and particularly trans-chalcone (1) is obtained with ACN (Figure 6A and Table 5). It is noticeable that the selectivity towards cis- and trans-chalcone ((1) + (2)) increases from 83 to $100 \%$ at the expense to that of the Michael addition product (3) which decreases from 17 to $8 \%$ when going from LDH/rGO-1 to LDH/rGO-5. This by-product is not formed with $\mathrm{LDH} / \mathrm{rGO}-10$ and $\mathrm{LDH} / \mathrm{rGO}-20$ as catalysts. This suggests the presence of a larger amount of stronger 
basic sites poisoned by ACN in these latter samples thus inhibiting the consecutive condensation of acetophenone and chalcone. LDH-rGO-20 and LDH-rGO-10 lead to the higher yields of trans-chalcone (1) and cis-chalcone (2), respectively and, most importantly, are totally selective for the formation of chalcone isomers. However, LDH-rGO-10 with a cis-chalcone (2) yield of 20\% exhibits a peculiar behaviour among the series of catalysts. No aldol product (4) was obtained with ACN as solvent, no matter the composition of the nanocatalysts. It is also remarkable that the $\mathrm{LDH} / \mathrm{rGO}$ nanocatalysts exhibit higher activity and selectivity towards trans- and cis-chalcone $(\mathbf{1}, \mathbf{2})$ than the calcined LDH (Table 5). Since this latter is the catalytically active phase in the nanocomposites, this proves the synergistic effect produced by the hybridization of LDH and rGO. This synergistic effect is assigned to the smaller size and the higher dispersion of the LDH crystallites on the rGO surface as showed by TEM.
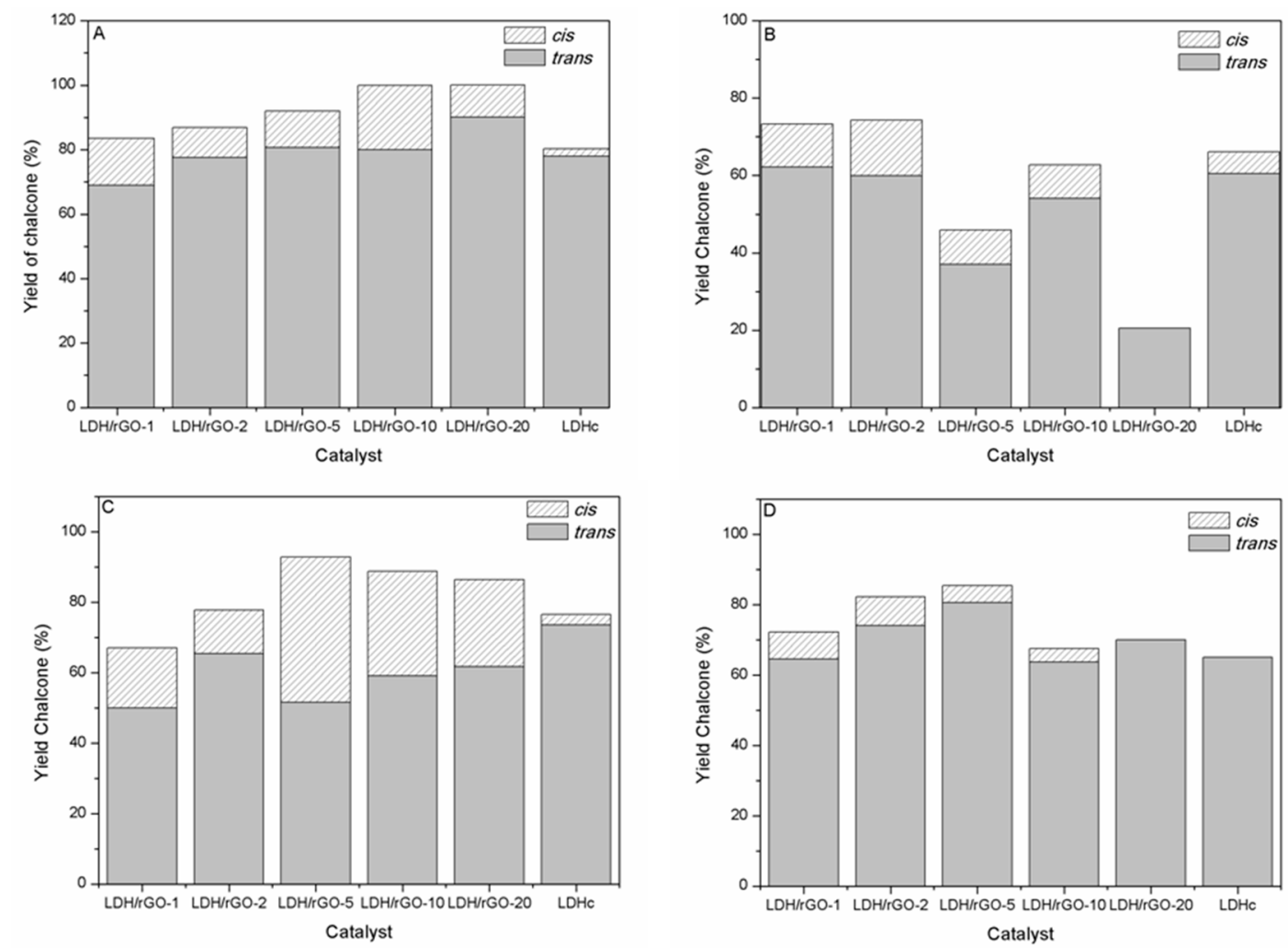

Figure 6. Chalcone yields obtained with the activated $\mathrm{LDH} / \mathrm{rGO}$ nanocatalysts and LDH in the different solvents: (A) acetonitrile; (B) methanol; (C) toluene and (D) without solvent.

When methanol is used as solvent cis-chalcone (2), trans-chalcone (1) and aldol (4) are only obtained while the Michael addition does not occur (Figure 6B and Table 6). There is a general trend towards a decrease of the chalcone yield $((\mathbf{1})+(2))$ at the expense of the aldol yield (4) as the LDH content in the $\mathrm{LDH} / \mathrm{rGO}$ nanocatalysts increases, except for LDH/rGO-10 again exhibiting a peculiar behaviour as already noted with ACN as solvent (Table 6 and Figure 6B). Moreover, the 1,4 addition of acetophenone on chalcone leading to the Michael addition product (3) is inhibited. LDH/rGO-1 and $\mathrm{LDH} / \mathrm{rGO}-2$ lead to the higher chalcone yields and exhibit similar behaviour than the calcined LDH in agreement with their closer basic properties. 
Table 6. Product yields after $4 \mathrm{~h}$ of reaction in methanol at $40{ }^{\circ} \mathrm{C}$ for all activated catalysts.

\begin{tabular}{|c|c|c|c|c|}
\hline \multirow[b]{2}{*}{ Catalyst } & Yield of $1(\%)$ & Yield of $2(\%)$ & Yield of $3(\%)$ & Yield of $4(\%)$ \\
\hline & & & & \\
\hline LDH/rGO-1 & 62 & 11 & - & 27 \\
\hline $\mathrm{LDH} / \mathrm{rGO}-2$ & 60 & 14 & - & 26 \\
\hline $\mathrm{LDH} / \mathrm{rGO}-5$ & 37 & 9 & - & 54 \\
\hline $\mathrm{LDH} / \mathrm{rGO}-10$ & 54 & 9 & - & 37 \\
\hline $\mathrm{LDH} / \mathrm{rGO}-20$ & 21 & - & - & 79 \\
\hline $\mathrm{LDH}^{*}$ & 60 & 6 & - & 30 \\
\hline
\end{tabular}

When toluene is used as solvent, trans-chalcone (1), cis-chalcone (2) and Michael addition product (3) were formed (Figure 6C and Table 7). A remarkable feature is that toluene gives rise to the higher cis-chalcone and Michael addition product yields among all the solvents studied, despite cis-chalcone being less thermodynamically stable than trans-chalcone due to the strong steric effects between the carbonyl group and the aryl ring.

Table 7. Product yields after $4 \mathrm{~h}$ of reaction in toluene at $40^{\circ} \mathrm{C}$ for all activated catalysts.

\begin{tabular}{lcccc}
\hline & Yield of $\mathbf{1}(\%)$ & Yield of 2 (\%) & Yield of $3(\%)$ & Yield of 4 (\%) \\
Catalyst & 50 & 17 & 33 & - \\
\hline $\mathrm{LDH} / \mathrm{rGO}-1$ & 65 & 13 & 22 & - \\
$\mathrm{LDH} / \mathrm{rGO}-2$ & 52 & 41 & 7 & - \\
$\mathrm{LDH} / \mathrm{rGO}-5$ & 50 & 11 & - \\
$\mathrm{LDH} / \mathrm{rGO}-10$ & 59 & 25 & 13 & - \\
$\mathrm{LDH} / \mathrm{rGO}-20$ & 62 & 3 & 12 & \\
$\mathrm{LDH}$ * & 73 & *After 8 h of reaction
\end{tabular}

Our catalytic results show that different chalcone isomer ratios are observed accounting for modifications of the interaction among reactants and the solvent, and depending on the composition of the catalysts whose polarity is related to the LDH:rGO weight ratio. Aromatic rings interact with the surface of rGO by competitive $\pi-\pi$ interactions. In the cases of ACN and methanol as solvents, the $\pi-\pi$ interaction between the reactants and the surface of the catalyst more likely occurs via a parallel orientation of the aromatic rings to the surface, thus favouring the formation of trans-chalcone. In the case of toluene as solvent, the interaction with both the surface of catalyst and the reactants is favoured due to their similar geometry and polarity. Moreover, reactants solvated by toluene are in less close proximity to the surface. This allows a T-shape $\pi-\pi$ interaction between aromatic rings of reactants and the surface of the catalyst increasing the formation of cis-chalcone (Scheme 4). 

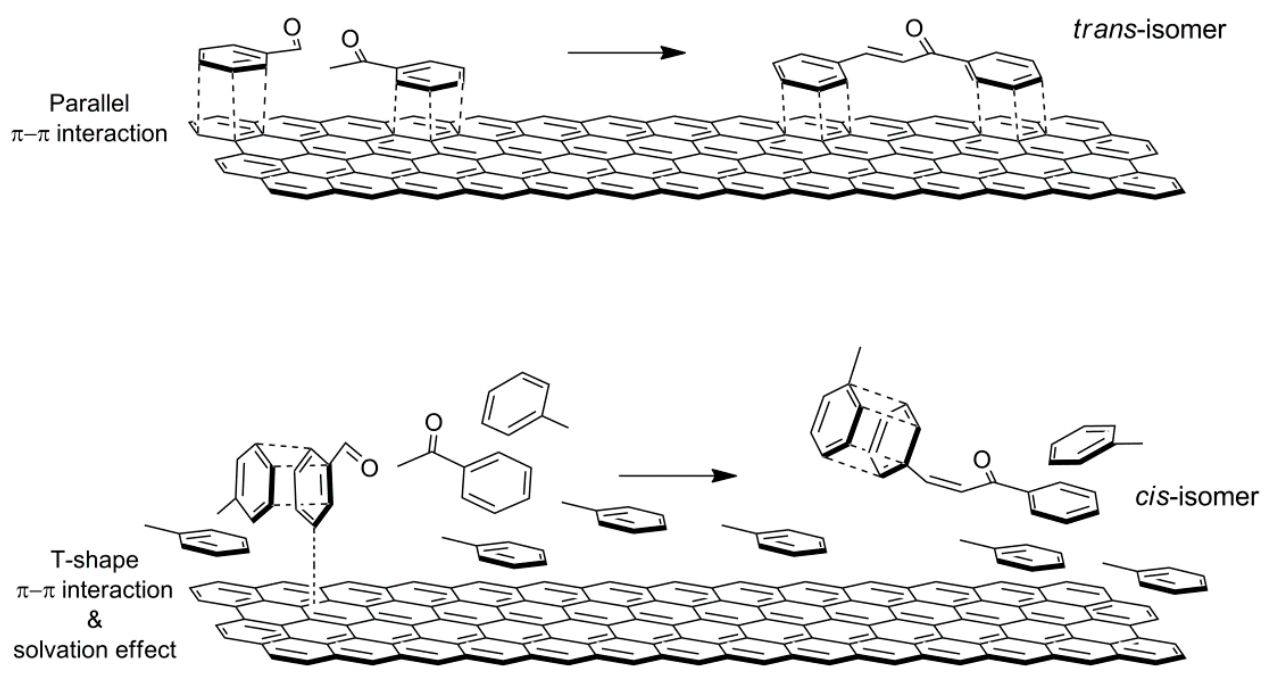

Scheme 4. $\pi-\pi$ interaction among solvent, reactants and the surface of the catalyst. Up: parallel interaction between aromatic rings and rGO surface with non-aromatic solvents. Down: T-shape interaction favoured by toluene solvation.

Cleaner synthetic routes, easier to handle, involving few or absence of solvent are currently desired in order to develop "green" processes. For this purpose and also to more finely define the $\mathrm{LDH} / \mathrm{rGO}$ nanocatalysts interaction with the reagents, a series of experiments were conducted without solvent (Figure 6D and Table 8). Chalcone, with a larger selectivity towards trans-chalcone (1) is the main product of reaction. Michael addition product (3) is the only by-product formed according to the high basicity of the samples. Aldol (4) is formed in the case of LDH/rGO-1 due the lower basicity of this sample in the series of nanocomposites.

Table 8. Product yields after $4 \mathrm{~h}$ of reaction without solvent at $40{ }^{\circ} \mathrm{C}$ for all activated catalysts.

\begin{tabular}{|c|c|c|c|c|}
\hline \multirow[b]{2}{*}{ Catalyst } & Yield of $1(\%)$ & \multirow{2}{*}{ Yield of $2(\%)$} & \multirow{2}{*}{ Yield of $3(\%)$} & \multirow{2}{*}{ Yield of $4(\%)$} \\
\hline & & & & \\
\hline $\mathrm{LDH} / \mathrm{rGO}-1$ & 65 & 8 & 10 & 17 \\
\hline $\mathrm{LDH} / \mathrm{rGO}-2$ & 77 & 10 & 13 & - \\
\hline $\mathrm{LDH} / \mathrm{rGO}-5$ & 81 & 5 & 14 & - \\
\hline $\mathrm{LDH} / \mathrm{rGO}-10$ & 64 & 4 & 32 & - \\
\hline $\mathrm{LDH} / \mathrm{rGO}-20$ & 70 & - & 30 & - \\
\hline $\mathrm{LDH}^{*}$ & 68 & - & 18 & - \\
\hline
\end{tabular}

It must be noted that higher Michael addition product yield is obtained without solvent than with $\mathrm{ACN}$ and toluene confirming the poisoning effect of these weakly acidic solvents on the strong basic sites. As expected, the Michael addition product yield also increases with the LDH content in the nanocomposites according to their increasing basicity. It reaches a maximum for the $\mathrm{LDH} / \mathrm{rGO}-10$ catalyst, which confirms its different behaviour compared to the other samples in the series. The increase of LDH content also decreased the selectivity towards the cis-chalcone, demonstrating that the presence of this product (thermodynamically unfavoured compared to trans-chalcone) in all the other experiments might be influenced by the presence of the solvent, which can act as stabilizer, especially in the case of toluene.

The results above reported show that the $\mathrm{LDH} / \mathrm{rGO}$ nanocomposites are efficient base catalysts for the Claisen-Schmidt condensation reaction between acetophenone and benzaldehyde. Due to the strong basicity of the catalysts, consecutive reaction leading to the Michael addition product occurs 
when the reaction is performed without solvent. However, performing the reaction in a slightly acidic solvent such as ACN allows obtaining total selectivity towards chalcone with the most basic $\mathrm{LDH} / \mathrm{rGO}-10$ and $\mathrm{LDH} / \mathrm{rGO}-20$ catalysts. The $\mathrm{LDH} / \mathrm{rGO}$ nanocatalysts are by far more active than the calcined LDH, and total conversion is obtained after $4 \mathrm{~h}$ at $40^{\circ} \mathrm{C}$ (against $8 \mathrm{~h}$ for bare LDH). This shows that the dispersion of the active $\mathrm{Mg}(\mathrm{Al}) \mathrm{O}$ mixed oxide phase in the activated nanocomposites creates strong and accessible $\mathrm{O}^{2-}$ basic sites which results in improved Lewis basicity compared to bare calcined LDH. The Brønsted-type basic sites in the calcined-rehydrated LDHs yet exhibit better efficiency than the Lewis-type basic sites in the LDH/rGO nanocomposites as reported in previous studies $[15,18]$. However, since the superior activity of the LDH/rGO catalysts with respect to bare calcined LDH has been proved, LDH/rGO materials are expected to boost their activity after proper rehydration/reconstruction. It must be point out that the objective of this work was to demonstrate that calcined $\mathrm{LDH} / \mathrm{rGO}$ hybrids have fine properties which make them active heterogeneous base catalysts in different reactions of interest. The nature of sites was not investigated. So, catalysis with rehydrated hybrids was not included in this manuscript. The rehydration procedure (i.e. gas or liquid phase), time, temperature and even drying mode are parameters known to strongly affect the final catalyst properties. Furthermore, rehydration depends on the characteristics of the hybrid itself (i.e. loading of LDH, type of preparation and drying...) and could be kinetically limited. So that efforts are still needed to make a protocol that allows obtaining rehydrated samples accurately and in a reproducible way.

\section{Summary and Conclusions}

Here, it has been demonstrated that $\mathrm{LDH} / \mathrm{rGO}$ nanomaterials present Lewis-type basic properties which are highly tunable. TEM analysis revealed the intimate contact between the LDH and graphene components in all the cases. The basic properties of the thermally activated $\mathrm{LDH} / \mathrm{rGO}$ materials were evaluated by $\mathrm{CO}_{2}$ adsorption, finding that the number of sites, was dependant on the LDH:rGO mass ratio. The physico-chemical properties of the LDH/rGO samples of different compositions were mirrored on their catalytic activity higher than that showed by bare LDH. Thus, total conversion at $40{ }^{\circ} \mathrm{C}$ was obtained after $4 \mathrm{~h}$ and $8 \mathrm{~h}$ over $\mathrm{LDH} / \mathrm{rGO}$ nanocatalysts and bare $\mathrm{LDH}$, respectively. The superior activity of the $\mathrm{LDH} / \mathrm{rGO}$ nanocatalysts accounts for the great dispersion of the active $\mathrm{Mg}(\mathrm{Al}) \mathrm{O}$ mixed oxide nanoplatelets, which creates strong and accessible $\mathrm{O}^{2-}$ basic sites, especially at higher amount of LDH, i.e., for LDH/rGO-10 and LDH/rGO-20. Remarkably, these two catalysts presented total selectivity towards the chalcone isomers in appropriate conditions, since the solvent plays an important role on the products distribution.

The specific behaviour of LDH/rGO nanocatalysts was observed when the reaction was performed in absence of solvent, where high yields of Michael addition product (3) were observed, especially with $\mathrm{LDH} / \mathrm{rGO}-10$ and $\mathrm{LDH} / \mathrm{rGO}-20$. This clearly indicates that basic sites present in the nanocomposite catalysts favour the subsequent condensation via 1,4-addition of acetophenone on chalcone in contrast to the rehydrated LDHs [14,17]. This further highlights the high strength of the Lewis-type basic sites generated by hybridization of LDH and rGO required for the Michael addition. On the contrary, the weak-medium strength of the Brønsted-type basic sites in the rehydrated LDHs cannot undergo 1,4-addition of acetophenone to chalcone.

Lopez et al. and Climent et al. $[15,18]$ have reported higher activity for calcined/rehydrated LDH at $150{ }^{\circ} \mathrm{C}$ than $\mathrm{LDH} / \mathrm{rGO}$ catalysts. However, the later present advantages such as high catalytic activity and selectivity towards chalcone under very soft liquid phase conditions $\left(40^{\circ} \mathrm{C}\right)$. Besides, $\mathrm{LDH} / \mathrm{rGO}$ materials are expected to boost their activity after proper rehydration/reconstruction.

The high activity of $\mathrm{LDH} / \mathrm{rGO}$ nanocatalysts, in combination with their high tunability through their composition, makes these materials promising candidates as solid base catalysts, opening a path to new applications of graphene-based nanocomposites which should be further studied. 
Author Contributions: M.G.Á., D.T. and D.G.C. conceived and designed the experiments; M.G.Á., D.G.C. and D.T. interpreted the data and wrote the paper; M.G.Á. synthesized and characterized the materials; D.G.C. performed catalytic tests and characterized the reaction products. M.G.Á., D.T., F.M. and D.G.C. read, corrected, and approved the final version of manuscript.

Funding: This research has been supported by the People Programme (Marie Curie Actions) of the European Union's Seventh Framework Programme (FP7/2007-2013) and from ACCIÓ under REA (grant agreement $\mathrm{n}^{\circ}$ 600388) through the grant TECSPR13-1-0038, Tecniospring-Marie Curie fellowship Programme.

Acknowledgments: The authors are also grateful to Servei de Recursos Cientifics i Tecnics of URV for the support during use of TEM, SEM and X-ray equipment.

Conflicts of Interest: The authors declare no conflict of interest.

\section{References}

1. Ferrer, D.I. Supported Layered Double Hydroxides as $\mathrm{CO}_{2}$ Adsorbents for Sorption-enhanced $\mathrm{H}_{2}$ Production; Springer: Berlin, Germany, 2014.

2. Zhao, M.Q.; Zhang, Q.; Huang, J.Q.; Wei, F. Hierarchical nanocomposites derived from nanocarbons and layered double hydroxides-Properties, synthesis and applications. Adv. Funct. Mater. 2012, 22, 675-694. [CrossRef]

3. Modesto-López, L.B.; Chimentão, R.J.; Álvarez, M.G.; Rosell-Llompart, J.; Medina, F.; Llorca, J. Direct growth of hydrotalcite nanolayers on carbon fibers by electrospinning. Appl. Clay Sci. 2014, 101, 461-467. [CrossRef]

4. Dubey, A. Synthesis and catalytic applications of CMK-LDH (layered double hydroxides) nanocomposite materials. Green Chem. 2007, 9, 424-426. [CrossRef]

5. Winter, F.; van Dillen, A.J.; de Jong, K.P. Supported hydrotalcites as highly active solid base catalysts. Chem. Commun. 2005, 3977-3979. [CrossRef] [PubMed]

6. Álvarez, M.G.; Frey, A.M.; Bitter, J.H.; Segarra, A.M.; de Jong, K.P.; Medina, F. On the role of the activation procedure of supported hydrotalcites for base catalyzed reactions: Glycerol to glycerol carbonate and self-condensation of acetone. Appl. Catal. B Environ. 2013, 134-135, 231-237. [CrossRef]

7. Celaya Sanfiz, A.; Morales-Vega, V.; De Marco, M.; Iruretagoyena, D.; Mokhtar, M.; Bawaked, S.M.; Basahel, S.N.; Al-Thabaiti, S.A.; Alyoubi, A.O.; Shaffer, M.S.P. Self-condensation of acetone over Mg-Al layered double hydroxide supported on multi-walled carbon nanotube catalysts. J. Mol. Catal. A Chem. 2015, 398, 50-57. [CrossRef]

8. Daud, M.; Kamal, M.S.; Shehzad, F.; Al-Harthi, M.A. Graphene/layered double hydroxides nanocomposites: A review of recent progress in synthesis and applications. Carbon 2016, 104, 241-252. [CrossRef]

9. Ahmed, N.S.; Menzel, R.; Wang, Y.; Garcia-Gallastegui, A.; Bawaked, S.M.; Obaid, A.Y.; Basahel, S.N.; Mokhtar, M. Graphene-oxide-supported $\mathrm{CuAl}$ and $\mathrm{CoAl}$ layered double hydroxides as enhanced catalysts for carbon-carbon coupling via Ullmann reaction. J. Solid State Chem. 2017, 246, 130-137. [CrossRef]

10. Álvarez, M.G.; Tichit, D.; Medina, F.; Llorca, J. Role of the synthesis route on the properties of hybrid LDH-graphene as basic catalysts. Appl. Surf. Sci. 2017, 396, 821-831. [CrossRef]

11. Aksoz, B.E.; Ertan, R. Chemical and Structural Properties of Chalcones I. FABAD J. Pharm. Sci. 2011, 36, 223-242.

12. Chimenti, F.; Fioravanti, R.; Bolasco, A.; Chimenti, P.; Secci, D.; Rossi, F.; Yáñez, M.; Orallo, F.; Ortuso, F.; Alcaro, S. Chalcones: A valid scaffold for monoamine oxidases inhibitors. J. Med. Chem. 2009, 52, 2818-2824. [CrossRef] [PubMed]

13. Mahapatra, D.K.; Bharti, S.K.; Asati, V. Anti-cancer chalcones: Structural and molecular target perspectives. Eur. J. Med. Chem. 2015, 98, 69-114. [CrossRef] [PubMed]

14. Hargrove-Leak, S.C.; Amiridis, M.D. Substitution effects in the heterogeneous catalytic synthesis of flavanones over MgO. Catal. Commun. 2002, 3, 557-563. [CrossRef]

15. Climent, M.J.; Corma, A.; Iborra, S.; Velty, A. Activated hydrotalcites as catalysts for the synthesis of chalcones of pharmaceutical interest. J. Catal. 2004, 221, 474-482. [CrossRef]

16. Solhy, A.; Tahir, R.; Sebti, S.; Skouta, R.; Bousmina, M.; Zahouily, M.; Lazrek, M. Efficient synthesis of chalcone derivatives catalyzed by re-usable hydroxyapatite. Appl. Catal. A 2010, 374, 189-193. [CrossRef] 
17. Jioui, I.; Danoun, K.; Solhy, A.; Jouiad, M.; Zahouily, M.; Essaid, B.; Len, C.; Fihri, A. Modified fluorapatite as highly efficient catalyst for the synthesis of chalcones via Claisen-Schmidt condensation reaction. J. Ind. Eng. Chem. 2016, 39, 218-225. [CrossRef]

18. Lopez, J.; Jacquot, R.; Figueras, F. Heterogeneous catalysis of aldolisations on activated hydrotalcites. Stud. Surf. Sci. Catal. 2000, 130, 491-496.

19. Guida, A.; Lhouty, M.H.; Tichit, D.; Figueras, F.; Geneste, P. Hydrotalcites as base catalysts. Kinetics of Claisen-Schmidt condensation, intramolecular condensation of acetonylacetone and synthesis of chalcone. Appl. Catal. A 1997, 164, 251-264. [CrossRef]

20. Hummers, W.S.; Offeman, R.E. Preparation of graphitic oxide. JACS 1958, 80, 1339. [CrossRef]

21. Álvarez, M.G.; Chimentão, R.J.; Figueras, F.; Medina, F. Tunable basic and textural properties of hydrotalcite derived materials for transesterification of glycerol. Appl. Clay Sci. 2013, 58, 16-24. [CrossRef]

22. Zhitova, E.S.; Krivovichev, S.V.; Pekov, I.V.; Yakovenchuk, V.N.; Pakhomovsky, Y.A. Correlation between the $d$-value and the $\mathrm{M}^{2+}: \mathrm{M}^{3+}$ cation ratio in $\mathrm{Mg}-\mathrm{Al}-\mathrm{CO}_{3}$ layered double hydroxides. App. Clay Sci. 2016, 130, 2-11. [CrossRef]

23. Garcia-Gallastegui, A.; Iruretagoyena, D.; Gouvea, V.; Mokhtar, M.; Asiri, A.M.; Basahel, S.N.; Al-Thabaiti, S.A.; Alyoubi, A.O.; Chadwick, D.; Shaffer, M.S.P. Graphene oxide as support for layered double hydroxides: Enhancing the $\mathrm{CO}_{2}$ adsorption capacity. Chem. Mater. 2012, 24, 4531-4539. [CrossRef]

24. Cai, X.; Shen, X.; Ma, L.; Ji, Z.; Xu, C.; Yuan, A. Solvothermal synthesis of NiCo-layered double hydroxide nanosheets decorated on RGO sheets for high performance supercapacitor. Chem. Eng. J. 2015, 268, 251-259. [CrossRef]

25. Mills, S.J.; Christy, A.G.; Genin, J.-M.R.; Kameda, T.; Colombo, F. Nomenclature of the hydrotalcite supergroup: Natural layered double hydroxides. Mineral. Mag. 2012, 76, 1289-1336. [CrossRef]

26. Iruretagoyena, D.; Shaffer, M.S.P.; Chadwick, D. Adsorption of carbon dioxide on graphene oxide supported layered double oxides. Adsorption 2014, 20, 321-330. [CrossRef]

27. Garcia-Gallastegui, A.; Iruretagoyena, D.; Mokhtar, M.; Asiri, A.M.; Basahel, S.N.; Al-Thabaiti, S.A.; Alyoubi, A.O.; Chadwick, D.; Shaffer, M.S.P. Layered double hydroxides supported on multi-walled carbon nanotubes: Preparation and $\mathrm{CO}_{2}$ adsorption characteristics. J. Mater. Chem. 2012, 22, 13932-13940. [CrossRef]

28. Lopez, J.; Sanchez-Valente, J.; Clacens, J.-M.; Figueras, F. Hydrogen Transfer Reduction of 4-tert-Butylcyclohexanone and Aldol Condensation of Benzaldehyde with Acetophenone on Basic Solids. J. Catal. 2002, 208, 30-37. [CrossRef] 